\title{
VIOLENCIA SIMBÓLICA Y EPISTÉMICA EN EL PERIODISMO INFORMATIVO. EL ANTIGITANISMO COMO ESTUDIO DE CASO
}

\author{
Symbolic and Epistemic Violence in Informative Journalism. Antigypsyism as \\ Case Study \\ Ismael Cortés Gómez \\ Universitat Jaume I \\ ismaelcortes_@hotmail.com
}

\section{Resumen:}

Este artículo lleva a cabo un análisis del framing que usa el periodismo informativo español para representar a la identidad "Gitana" bajo los signos de la peligrosidad y la criminalidad (período 2010-2018). El artículo se construye a partir de la siguiente hipótesis: bajo las formas de la violencia simbólica y la violencia epistémica, el antigitanismo legitima la discriminación estructural contra la población gitana en España. El artículo está organizado en cinco secciones: primero, se introduce un marco analítico a través de las nociones de "antigitanismo", "discriminación estructural", "violencia simbólica", "violencia epistémica", "framing analysis" y "miedo social". Segundo, el artículo presenta un estudio de caso, basado en una muestra de 150 noticias nacionales que representan a protagonistas de identidad gitana bajo un enfoque sesgadamente racista. Tercero, este análisis nos habilita a plantear un debate ético y legal que indaga los límites de la libertad de expresión, respecto del uso del lenguaje discriminatorio en las narrativas informativas. La cuarta sección incluye un apartado de conclusiones que examina la correlación entre la discriminación estructural antigitana y el papel de los medios de comunicación en la construcción del estigma de la "amenaza gitana". Por último, el artículo indica una serie de recomendaciones que podrían emplearse para contrarrestar el racismo en las narrativas informativas.

\section{Palabras clave:}

Antigitanismo, discriminación estructural, framing análisis, violencia simbólica, violencia epistémica, miedo social, lenguaje discriminatorio

\begin{abstract}
:
This study conducted a framing analysis of how Spanish journalism represents the "Gypsy identity" within the marks of dangerousness and criminality (period 2010-18). The paper aims to validate the following underpinning hypothesis: as symbolic and epistemic violence, antigypsyism legitimises systemic racial discrimination and exclusion against the Roma people in Spain. The article is organised into five sections: first, an analytical framework introduces the notions of
\end{abstract}


'antigypsyism', 'structural discrimination', 'social fear', 'symbolic violence', 'epistemic violence' and 'framing analysis'. Second, a tangible case study is presented on a sample of 150 national news reports that portray Roma characters in a biased way. Third, this analysis enabled an ethical and legal debate that challenges the limits of free speech and the uses of discriminatory language in informative narratives. The fourth section includes some conclusions examining the correlation between antigypsyistic structural discrimination and the role of media in engendering the stigma of the "Gypsy threat". Finally, the article indicates a series of recommendations that could be used to counteract racism in news narratives.

\section{Keywords:}

Antigypsyism, Structural discrimination, Framing analysis, Symbolic violence, Epistemic violence, Social fear, Discriminatory language

Recibido: 05/12/2019

Aceptado: 21/12/2019

\section{INTRODUCCIÓN: MARCO ANALÍTICO}

En la época poscolonial actual, la discriminación por motivos étnicos o raciales está prohibida por mandato constitucional en todas las democracias del mundo. No obstante, las estructuras de discriminación racial siguen operando en sus formas simbólicas y epistémicas, consolidando la percepción de una sociedad estratificada en base a divisiones morales y a relaciones inter-étnicas conflictivas. Una percepción que vincula la autoría de determinados comportamientos criminales o delictivos con protagonistas pertenecientes a determinados grupos étnico-raciales.

El objetivo general de este artículo es poner de relieve la responsabilidad de los medios de comunicación, tanto públicos como privados, en la promoción de la igualdad y la no discriminación de las minorías étnico-raciales; y más concretamente en la prevención del antigitanismo. Específicamente, este artículo procura responder a una pregunta fundamental: ¿cómo contribuye el framing de las narrativas informativas a construir el estigma de la "amenaza gitana"?

En los últimos años, la noción de "antigitanismo" ha recibido una atención creciente de los ámbitos políticos y académicos en Europa (Parlamento Europeo [EP], 2015, 2017; Agencia de Derechos Fundamentales de la Unión Europea [FRA], 2018; Agarin, 2014; End y Selling, 2015; Cortés y End, 2019; Carrera et al., 2018; Carrera et al., 2019). Como resultado, se han propuesto las siguientes definiciones diferentes (y complementarias) desde el nivel institucional y desde la sociedad civil:

- El antigitanismo es una forma específica de racismo, una ideología fundada en la superioridad racial, una forma de deshumanización y racismo institucional alimentado por la discriminación histórica, que se expresa, entre otras cosas, por la violencia, el discurso de odio, la explotación, la estigmatización y el tipo más flagrante de discriminación 
(Comisión Europea contra el Racismo y la Intolerancia [ECRI], 2011).

- El antigitanismo es una forma específica del racismo dirigido hacia las personas gitanas, de forma similar al antisemitismo: i) es persistente tanto histórica como geográficamente (es permanente y no disminuye); ii) es sistemático (es aceptado por prácticamente toda la comunidad) y iii) a menudo va acompañado de actos de violencia y discriminación (Consejo de Europa [CoE], 2012).

- El antigitanismo es una forma compleja -construida históricamente- de racismo tradicional contra grupos sociales identificados bajo el estigma "Gitano [Gypsy]"1 u otros términos relacionados e incorpora: 1. Una percepción esencializante y homogeneizadora de estos grupos. 2. La atribución de características específicas a dichos grupos. 3. Estructuras sociales discriminatorias y prácticas violentas que surgen en ese contexto, que tienen un efecto degradante y de exclusión y que reproducen las desigualdades estructurales (Alliance Against Antigypsyism, 2017).

La lucha contra el antigitanismo se inscribe en una tradición más amplia de lucha contra la discriminación racial. La Convención Internacional sobre la Eliminación de todas las Formas de Discriminación Racial (ICERD siglas en inglés) establece la siguiente definición:

El término "discriminación racial" significará cualquier distinción, exclusión, restricción o preferencia basada en la raza, el color, la ascendencia u origen nacional o étnico, que tenga el propósito o efecto de anular o perjudicar el reconocimiento, disfrute o ejercicio, en igualdad de condiciones, de los derechos humanos y las libertades fundamentales, en el ámbito político, económico, social, cultural o cualquier otro de la vida pública (ICERD, 1965).

La citada Convención Internacional sobre la Eliminación de todas las Formas de Discriminación Racial resolvió

\footnotetext{
1 Como explica Petrova, el término 'Roma', que es la auto-denominación etnocultural de muchas de las personas que los no gitanos perciben como 'gitanos' [Gypsies], domina el discurso político oficial y ha adquirido la legitimidad de la corrección política (Petrova, 2003). Tal y como ha explicado Hancock (2002), el etnónimo "Gypsy" fue introducido y utilizado por error en el Reino Unido durante los siglos XVI-XVII. La población no romaní de entonces en el Reino Unido utilizó el término "Gypsy" basándose en la interpretación errónea de que el pueblo romaní provenía de Egipto. El endónimo original en romaní para llamarse a sí mismos es "Rom" (hombre), "Romni" (mujer) y "Roma" (genérico plural). En 2012, la Comisión Europea inició el proceso de implementación del Contexto Europeo de Estrategias Nacionales de Inclusión de los Gitanos y proporcionó la siguiente definición: 'el término "Roma" se usa aquí, y en varias organizaciones internacionales y representantes de grupos gitanos en Europa, para referirse a varios grupos diferentes (por ejemplo, Roma, Sinti, Kale, Gitanos, Romanichels, Boyash, Ashkali, Egyptians, Yenish, Dom y Lom) y también incluye a los Travellers, sin negar las especificidades y variedades de estilos de vida y situaciones de estos grupos". (Comisión Europea [CE], 2012).
} 
adoptar todas las medidas necesarias para eliminar rápidamente la discriminación racial en todas sus formas y manifestaciones, y prevenir y combatir las doctrinas y prácticas racistas con el fin de promover el entendimiento entre las razas y edificar una comunidad internacional libre de todas las formas de segregación y discriminación raciales (ICERD, 1965).

En términos más actuales, de acuerdo con la Directiva de Igualdad Racial de la Unión Europea, la "discriminación racial o étnica" incluye los siguientes casos: el acceso o tratamiento desigual de ciertos grupos en áreas como el empleo, la educación, la seguridad, la atención médica, la vivienda y el acceso a bienes y servicios (Directiva 2000/43 / CE). Según el Consejo Económico y Social de las Naciones Unidas (ECOSOC), el estudio de las situaciones de "exclusión" y "discriminación" no debe únicamente describir un determinado estado de privación de derechos fundamentales, sino que ha de incluir un análisis del proceso cultural y económico que conduce a ese estado y lo sostiene (ECOSOC, 2018).

Este artículo dialoga con estudios recientes que han analizado las nociones de "discriminación" y "exclusión" estructural relacionadas con el antigitanismo. Sigona y Vermeersch (2012) y Kostka (2019) explican que la discriminación antigitana se deriva fundamentalmente de una situación sistémica de segregación espacial y pobreza intergeneracional. ${ }^{2}$ En esta línea, Picker (2017) ha explicado que en Europa se pueden observar áreas urbanas segregadas, que están parcial o completamente ocupadas por hogares gitanos. Estos espacios, por lo general, tienen tasas de desempleo más altas que otras áreas, presentan pocos o ningún servicio público, viviendas de calidad inferior, educación de baja calidad, infraestructura sanitaria inadecuada y estigmatización severa. ${ }^{3}$

Ryder y Taba (2017) se han centrado en las potencialidades de la redistribución económica para combatir el antigitanismo; y recomiendan medidas activas de bienestar social y una fuerte inversión pública para la creación de empleo. Kovats y Law (2018) y Rostas (2019) han puesto el énfasis en la democratización de los procesos de diseño de políticas públicas y en la construcción de una ciudadanía activa. Estos autores afirman que el aumento de la conciencia política de las personas gitanas, ${ }^{4}$ y en consecuencia, la representación de sus intereses en los

\footnotetext{
${ }^{2}$ Ver anexos donde se recogen datos multisectoriales de fuentes oficiales que reflejan la situación de discriminación estructural de la población gitana en España.

${ }^{3}$ En España, estudios recientes han aportado datos de 2.604 barrios/asentamientos gitanos segregados correspondientes a 1.069 municipios (Laparra, 2011; La Parra-Casado y Jiménez González, 2016; Ministerio de Sanidad, Servicios Sociales e Igualdad, 2016).

${ }^{4}$ Como explican Matache y Oprea (2019), las palabras "Gypsy" (en inglés), "Tigan" (en rumano), y sus variaciones han sido ampliamente reconocidas como ofensivas, o al menos, como nombres incorrectos. La palabra "Gitano" (en español) incluye ciertos matices, aunque incluye también acepciones peyorativas o estereotipadas. GITANO, A (etimología: de egiptano, porque se creía que procedían de Egipto). 1. adj. Dicho de una persona: de un pueblo originario de la India, extendido por diversos países, que ha mantenido el nomadismo
} 
procesos de toma de decisiones, puede ser un elemento crucial para realizar transformaciones sistémicas y eliminar la discriminación. Por otro lado, Kocze y Rövid (2019) y End (2019) han insistido en el poder de los medios de comunicación y de los discursos políticos para cuestionar los prejuicios antigitanos profundamente arraigados; y para deconstruir los mecanismos culturales de diferenciación o alterización binaria.

La contribución original de este artículo a la crítica teórica y política del antigitanismo es la siguiente: por un lado, profundizar en los fundamentos éticosemánticos de las narrativas informativas; $y$, por otro lado, explicar las conexiones entre los procesos simbólicos y materiales de discriminación y exclusión. Este artículo analiza el uso de los marcos simbólicos y epistémicos como un mecanismo central del antigitanismo. Así, el artículo se construye a partir de los conceptos de "violencia simbólica" (Bourdieu, 1979) y "violencia epistémica" (Spivak, 1994; Spivak y Guha, 1988). La definición clásica de Bourdieu del poder simbólico es la siguiente:

El poder de construir la realidad, que tiende a establecer un orden gnoseológico, genera el consenso sobre el sentido de un mundo social, lo cual supone una contribución fundamental para reproducir el orden social; la integración 'lógica' es la precondición de la integración 'moral' [...] La cultura dominante produce su efecto ideológico específico al ocultar su función de división (o distinción) bajo su función de comunicación: la cultura que une (un medio de comunicación), separa (un instrumento de distinción) y legitima las distinciones definiendo todas las culturas (designadas como subculturas) en términos de su distancia de la cultura dominante (Bourdieu, 1979: 79-80).

El concepto original de violencia epistémica, acuñado por Spivak, se centra en el sujeto colonial de la siguiente manera:

El ejemplo más claro que conocemos de esta violencia epistémica es el proyecto orquestado de forma remota, lejano y heterogéneo para constituir al sujeto colonial como Otro. Este proyecto es también la anulación asimétrica de la huella de ese Otro en su precaria subjetividad. Es bien sabido que Foucault ubica la violencia epistémica, una revisión completa de la episteme, en la redefinición de la cordura a fines del siglo XVIII europeo. Pero, iy si esa redefinición en particular fuera solo una parte de la narrativa de la historia en Europa y en las colonias? ¿Y si los dos proyectos de revisión epistémica funcionaran como partes disociadas y no reconocidas de un gran motor? (Spivak, 1994: 76).

y ha conservado rasgos físicos y culturales propios. 2. adj. Perteneciente o relativo a los gitanos. 3. adj. Propio de los gitanos, o parecido a ellos. 4. adj. caló (perteneciente al caló). Léxico gitano. 5. adj. Trapacero, usado como ofensivo o discriminatorio. 6. adj. Que tiene gracia y arte para ganarse las voluntades de los demás, y especialmente referido a una mujer. 7. adj. Egipcio (natural de Egipto). 8. Sustantivo. Caló (variedad del romaní) (RAE, 2018). 
Diferentes autores poscoloniales han explicado que, en el período posterior al apartheid y tras la consecuente globalización de las leyes antirracistas, la discriminación racial se volvió predominantemente simbólica y epistémica, (re)articulando así divisiones morales y jerarquías sociales (Bhabha, 2011; Mbembe, 2017; Carty y Chandra, 2018). Por lo tanto, la lucha por la justicia racial debe tomar nuevas formas para desarrollar (de nuevo) estrategias de inclusión universal. En esta lucha por la igualdad, los nuevos enfoques para cuestionar(se) y reapropiar(se) el poder simbólico y epistémico son cruciales, si queremos transformar las bases éticas y políticas de las relaciones raciales de dominación.

Se han producido diferentes desarrollos del concepto de violencia epistémica (Bartels et al., 2019). En estudios recientes, se ha analizado la violencia epistémica como una categoría aplicable a sujetos no coloniales, es decir, a cualquier víctima de un sistema de dominación desarrollado sobre relaciones de saber / poder:

La violencia epistémica, es decir, la violencia ejercida contra o a través del saber, es probablemente uno de los elementos clave en cualquier proceso de dominación. No es solo a través de la construcción de vínculos económicos de explotación o el control de los aparatos políticomilitares como se logra la dominación, sino también - y yo diría que sobre todo- a través de la construcción de contextos epistémicos que legitiman y consagran esas prácticas de dominación (Galván Alvárez, 2010: 11).

La aplicación de un enfoque analítico dual, cognitivo y afectivo, hacia el estudio del racismo es especialmente relevante para el objetivo que persigue el presente estudio. En este sentido, es de especial interés el concepto de "activismo epistémico", acuñado por Medina (2019):

[el activismo epistémico] se refiere a las actividades críticas de denunciar, cuestionar y oponerse a las actitudes cognitivo- afectivas y a las sensibilidades (o falta de sensibilidad) que facilitan la complicidad con la opresión racial y la violencia racial. Mi análisis presta especial atención al papel que juega la afectividad en la complicidad con la violencia racial y cómo las actitudes afectivas pueden usarse en el activismo epistémico para acabar con la complicidad y movilizar a las personas en la lucha contra la violencia racial (Medina, 2019: 22).

En el análisis del framing periodístico que se realiza en este artículo, entendemos que las narrativas informativas al definir un problema social no solo explican sus causas, sino que también emiten juicios morales sobre los responsables, induciendo determinados sentimientos hacia éstos. Por lo tanto, asumimos que las narrativas informativas no solo construyen marcos cognitivos (Kelsey, 2017; Jakobsson y Stiernstedt, 2018), sino que construyen también marcos afectivos de interpretación (De los Santos et al, 2019). El framing implica un patrón retórico que, además de conexiones lógicas, activa conexiones afectivas que pautan la lectura de la información. 
En lo que se refiere al contenido afectivo del patrón retórico implicado en el framing informativo, este artículo focaliza en la dimensión social del miedo y en la construcción del estigma de la "amenaza gitana". En los términos analizados, el "miedo" no es un sentimiento que afecta a un sujeto individual, en un momento particular de su existencia. Estudiamos el "miedo" como un sentimiento que afecta a una parte importante de la población, de una manera sostenida en el tiempo, como resultado de una percepción colectiva construida mediáticamente. En el caso de la inducción del "miedo social", en relación al racismo, son de especial interés los estudios de Hurley (2015). En el contexto estadounidense, analizó la construcción de la percepción del miedo a la delincuencia en las noticias de televisión; y encontró una cobertura desproporcionada, en relación a variables étnico-raciales, con una (sobre)representación de afroamericanos como agresores y blancos como víctimas.

Más allá de realizar un análisis semántico-formal, este artículo se encarga de estudiar las funciones socio-políticas de la violencia simbólica y la violencia epistémica, en relación al antigitanismo: a) el daño a la reputación de un determinado sujeto colectivo; b) la construcción de una opinión pública basada en el miedo; c) la legitimación de una situación de discriminación y exclusión estructural.

\section{ESTUDIO DE CASO: FRAMING ANALYSIS DEL ANTIGITANISMO EN LOS MEDIOS}

En una primera búsqueda, encontramos 1.200 noticias referidas al contexto español, que contenían una asociación semántica explícita entre la autoría de actos criminales o delictivos y protagonistas significados como pertenecientes a la etnia gitana. Debido a la dispersión de esta primera muestra, que incluía una gran variedad de medios escritos y televisados (tanto locales como autonómicos o nacionales), decidimos construir este estudio de caso a partir de una muestra más precisa y concreta (ver anexos). Seleccionamos 100 noticias publicadas por los periódicos de ámbito nacional más leídos, que incluyen tanto versión online como impresa: El País, ABC, La Razón y El Mundo (período 2010-2018). Esta muestra permite ver la reiteración de un mismo framing informativo a través del tiempo, y a través de todo el espectro editorial: desde periódicos con una línea editorial más cercana a la social-democracia hasta periódicos con una línea más liberal u otros con una línea más conservadora. Además, pudimos identificar el mismo framing en 50 noticias difundidas por cinco de los más destacados programas nacionales de noticias de televisión (líderes de audiencia): Informativos de TVE, Antena 3 Noticias, Informativos Telecinco, Noticias Cuatro y la Sexta Noticias (ver anexos).

En base a esta muestra, 150 noticias en total, el artículo lleva a cabo un análisis del framing periodístico que comprende el uso de un determinado léxico así como de un repertorio de imágenes concreto. Tal framing define: el autor del delito, la motivación y el escenario. Este framing ha sido utilizado indistinta y repetidamente por editoriales de noticias progresistas, liberales y conservadores. Por lo tanto, se puede observar un régimen monolítico de visibilidad. Este framing consolida la opinión pública en una dirección sesgada, asociando la identidad de las personas gitanas con la peligrosidad y la criminalidad, reforzando así el estigma de la "amenaza gitana". 


\begin{tabular}{|c|c|c|c|}
\hline Delito & Léxico & Imágenes de los protagonistas & Escenario Social \\
\hline $\begin{array}{l}\text { Asesinato } \\
\text { (dentro } \\
\text { del gueto) }\end{array}$ & $\begin{array}{l}\text { - Autor: clan gitano. } \\
\text { - Motivo: Venganza. }\end{array}$ & $\begin{array}{l}\text { - Familias gitanas afectadas. } \\
\text { - Mujeres mayores y niños llorando. } \\
\text { - Hombres mayores como mediadores. } \\
\text { - Intimidad de las familias gitanas (vida } \\
\text { cotidiana). } \\
\text { - Jóvenes gitanos y gitanas pidiendo venganza. }\end{array}$ & $\begin{array}{l}\text { Barrio en una zona } \\
\text { urbana segregada: } \\
\text { ruidoso, sucio y } \\
\text { deteriorado. }\end{array}$ \\
\hline $\begin{array}{l}\text { Asesinato } \\
\text { (fuera } \\
\text { del gueto) }\end{array}$ & $\begin{array}{l}\text { - Autor: persona de etnia } \\
\text { gitana. } \\
\text { - Motivo: Crimen } \\
\text { pasional. }\end{array}$ & $\begin{array}{l}\text { - Jóvenes gitanos como criminales. } \\
\text { - Una persona inocente como víctima. } \\
\text { - Fuerzas policiales investigando el caso. } \\
\text { - Personas no gitanas como testigos. } \\
\text { - Vida profesional de la víctima. } \\
\text { - Familia de la víctima. }\end{array}$ & Una discoteca. \\
\hline $\begin{array}{l}\text { Tiroteo } \\
\text { (dentro } \\
\text { del gueto) }\end{array}$ & $\begin{array}{l}\text { - Autor: familia gitana. } \\
\text { - Motivo: Venganza. }\end{array}$ & $\begin{array}{l}\text { - Familias gitanas afectadas. } \\
\text { - Mujeres mayores y niños llorando. } \\
\text { - Hombres mayores como mediadores. } \\
\text { - Intimidad de las familias gitanas (vida } \\
\text { cotidiana). } \\
\text { - Jóvenes gitanos y gitanas pidiendo venganza. }\end{array}$ & $\begin{array}{l}\text { Barrio en una zona } \\
\text { urbana segregada: } \\
\text { ruidoso, sucio y } \\
\text { deteriorado. }\end{array}$ \\
\hline
\end{tabular}

\begin{tabular}{|c|c|c|c|}
\hline & El País, 8/8/2010 & La Razón, 7/8/2010 & $\mathrm{ABC}, 7 / 8 / 2010$ \\
\hline Titular & $\begin{array}{l}\text { Un hombre muere por un } \\
\text { disparo a la puerta de una } \\
\text { discoteca en Torrejón [una } \\
\text { ciudad]. }\end{array}$ & $\begin{array}{l}\text { Venganza en la 'Pícaro' } \\
\text { [nombre de la discoteca]. }\end{array}$ & $\begin{array}{l}\text { Un joven muere tras un } \\
\text { tiroteo a la puerta de una } \\
\text { discoteca en Torrejón. }\end{array}$ \\
\hline $\begin{array}{l}\text { Descripción de } \\
\text { los actores y } \\
\text { del contexto }\end{array}$ & $\begin{array}{l}\text { Los autores de los disparos } \\
\text { eran unos gitanos implicados } \\
\text { en una pelea con los guardias } \\
\text { de seguridad de la discoteca. } \\
\text { Un hombre, que no estaba } \\
\text { implicado en la pelea, murió } \\
\text { por un disparo de bala, en la } \\
\text { puerta de la discoteca. }\end{array}$ & $\begin{array}{l}\text { Un hombre fue alcanzado por } \\
\text { una bala "perdida" de una } \\
\text { reyerta entre un grupo de } \\
\text { gitanos y los porteros. }\end{array}$ & $\begin{array}{l}\text { Los autores del tiroteo eran } \\
\text { de etnia gitana y usaron la } \\
\text { fuerza contra los porteros de } \\
\text { la discoteca. Finalmente, los } \\
\text { autores dispararon a todos los } \\
\text { que estaban en la puerta en } \\
\text { ese momento. La persona } \\
\text { fallecida no tenía nada que } \\
\text { ver con la pelea. }\end{array}$ \\
\hline
\end{tabular}

Nota: El mismo caso fue publicado en noticias de periódicos progresistas, liberales y conservadores (El País, 2010; La Razón, 2010; ABC, 2010). 


\begin{tabular}{|c|c|c|c|}
\hline & El País, 21/5/2014 & El Mundo, 21/5/2014 & ABC, $22 / 5 / 2014$ \\
\hline Titular & $\begin{array}{l}\text { Seis personas detenidas por } \\
\text { una reyerta con armas en } \\
\text { Villena [una ciudad]. }\end{array}$ & $\begin{array}{l}\text { Seis personas detenidas por } \\
\text { su implicación en una reyerta } \\
\text { con armas. }\end{array}$ & $\begin{array}{l}\text { Seis detenidos en Villena por } \\
\text { una reyerta con armas de } \\
\text { fuego entre familias. }\end{array}$ \\
\hline $\begin{array}{l}\text { Descripción de los } \\
\text { actores y del } \\
\text { escenario social }\end{array}$ & $\begin{array}{l}\text { Las seis personas arrestadas } \\
\text { pertenecen a familias gitanas. } \\
\text { El altercado tuvo lugar en el } \\
\text { barrio de San Francisco [un } \\
\text { conocido "gueto gitano" de } \\
\text { la ciudad]. }\end{array}$ & $\begin{array}{l}\text { Seis personas implicadas en } \\
\text { una reyerta entre dos familias } \\
\text { gitanas. El altercado tuvo } \\
\text { lugar en el barrio de San } \\
\text { Francisco. }\end{array}$ & $\begin{array}{l}\text { Las seis personas arrestadas } \\
\text { pertenecen a dos familias } \\
\text { gitanas enfrentadas. Los } \\
\text { familiares de los detenidos } \\
\text { estuvieron presentes durante } \\
\text { el altercado. El altercado } \\
\text { tuvo lugar en el barrio de } \\
\text { San Francisco. }\end{array}$ \\
\hline
\end{tabular}

Nota: El mismo caso fue publicado en noticias de periódicos progresistas, liberales y conservadores (El País, 2014; El Mundo, 2014; ABC, 2014).

\begin{tabular}{|c|c|c|}
\hline & El Mundo, 2/9/2015 & $A B C, 2 / 9 / 2015$ \\
\hline Titular & $\begin{array}{l}\text { Un muerto y cinco heridos en una pelea entre } \\
\text { dos clanes de etnia gitana en Mazarrón [una } \\
\text { ciudad]. }\end{array}$ & $\begin{array}{l}\text { Un muerto y cinco hospitalizados por una } \\
\text { pelea entre dos clanes de etnia gitana en } \\
\text { Mazarrón. }\end{array}$ \\
\hline $\begin{array}{l}\text { Descripción de } \\
\text { los actores y } \\
\text { del escenario } \\
\text { social }\end{array}$ & $\begin{array}{l}\text { Los investigadores policiales declararon que } \\
\text { todo comenzó por la mañana con una } \\
\text { discusión entre dos familias enfrentadas. Horas } \\
\text { después, un automóvil golpeó } \\
\text { intencionalmente a una persona en medio de la } \\
\text { calle. A consecuencia de esto, los familiares de } \\
\text { la víctima fueron al área donde vivían los } \\
\text { presuntos autores y los atacaron, lo que resultó } \\
\text { en una pelea colectiva, con la muerte de una } \\
\text { mujer y varias personas heridas. }\end{array}$ & $\begin{array}{l}\text { Una discusión por la mañana entre dos } \\
\text { mujeres causó horas después una pelea } \\
\text { colectiva, en la que dos clanes gitanos se han } \\
\text { visto implicados. Después de la discusión, un } \\
\text { automóvil hirió intencionalmente a un peatón. } \\
\text { Luego, sus familiares fueron a buscar a los } \\
\text { miembros de la otra familia y provocaron una } \\
\text { pelea colectiva, en la que una de las mujeres } \\
\text { murió y tres personas resultaron gravemente } \\
\text { heridas. }\end{array}$ \\
\hline
\end{tabular}

Nota: El mismo caso fue publicado en noticias de medios liberales y conservadoras (El Mundo, 2015; ABC, 2015).

\section{Escenarios sociales}

La creación de un espacio de vida étnico dicotómico, dentro del gueto (espacio gitano) / fuera del gueto (espacio no gitano), es una construcción virtual promovida por las noticias. De acuerdo a recientes estudios sociológicos sobre vivienda (Hernández, 2013; EAPN, 2019), el índice de exclusión residencial en España es del $21 \%$. En esta cifra están incluidas personas y familias no gitanas que viven en barrios marginales (en áreas segregadas). La dicotomía étnico-racial espacial se ha radicalizado artificialmente en las narrativas informativas. De todos los escenarios sociales posibles, las noticias reiteran la imagen de las personas y las familias gitanas 
que viven dentro del gueto. Además, las noticias reiteran en imágenes de jóvenes gitanos que salen del gueto para causar problemas en locales de ocio nocturno.

\section{Imágenes de los protagonistas}

El repertorio de imágenes genera una asociación lógica entre una serie de crímenes individuales y único sujeto colectivo como autor virtual de todos ellos.

Las noticias presentaron los crímenes cometidos en el gueto como si fueran cometidos por todos los miembros de una familia gitana, y no por un individuo o por un grupo de individuos. La construcción virtual de la "familia gitana" establece el comportamiento criminal como un elemento inherente de la cultura; e implica que estos elementos violentos se heredan de generación en generación, por un vínculo de parentesco. La puesta en escena recrea la vida ordinaria del gueto y retrata la violencia como un comportamiento "natural" propio del espacio vital que habita el grupo étnico. Además, hace hincapié en los jóvenes gitanos que reclaman venganza después de un asesinato o una pelea. Esto implica un círculo vicioso de la violencia. La puesta en escena representa un estado interminable de violencia: lágrimas de desesperación y gritos de mujeres y niñas y niños gitanos, a pesar de los esfuerzos de los ancianos gitanos para mediar y llevar la paz.

En los crímenes cometidos fuera del gueto, las imágenes se centran menos en el autor (caracterizado como un joven "gitano") y más en la víctima, la policía y los testigos no gitanos. En estos casos, las imágenes se centran en la experiencia de los sujetos no gitanos que ven interrumpida su "vida normal" por causa de la acción criminal de un "sujeto gitano". Las descripciones de las noticias representan a la víctima como un "buen ciudadano" en oposición al "malvado gitano".

\section{Léxico}

Además de las imágenes de diferentes personajes étnicos y la construcción virtual de escenarios sociales, el uso del léxico es crucial para fijar la identidad del grupo en el imaginario colectivo.

En casos de asesinatos múltiples en el gueto, el actor colectivo gitano es etiquetado como un 'clan', con dos connotaciones principales: 1) En la jerga de la mafia, la palabra 'clan' se refiere a un grupo criminal dedicado a la venta de drogas ilegales, lavado de dinero y / o crimen organizado. 2) En antropología cultural, la palabra 'clan' se refiere a una modalidad de organización social pre-industrial, que aún puede existir en las sociedades modernas: es un grupo de ascendencia común que se rige por sus propias normas, instituciones y autoridades, paralelas a las del Estado. $^{5}$

En los casos de peleas colectivas con armas de fuego en el gueto, el actor colectivo gitano es etiquetado como una "familia gitana"; lo que enfatiza las asociaciones entre parentesco, pertenencia étnica y comportamiento criminal. En casos de asesinatos fuera del gueto, los textos de las noticias destacan la "etnia

${ }^{5}$ Sneath, D. (2016). Tribe. In Felix Stein et al. (eds) (2016) The Cambridge Encyclopedia of Anthropology. Disponible online http://www.anthroencyclopedia.com/entry/tribe (acceso 30 de junio de 2018). 
gitana" del autor, y no proporcionan otra motivación aparte del impulso de violencia contra una provocación suave. En todos los casos, el léxico empleado genera un distanciamiento cultural radical, es decir, irreconciliable entre la supuesta "moral gitana" y la moral de la sociedad mayoritaria. Así pues, las narrativas de las noticias refuerzan la dicotomía entre el "salvajismo gitano" y el mundo civilizado de la sociedad mayoritaria.

\section{DeBATE ÉTICO Y LEGAL: LOS LÍMITES DE LA LIBERTAD DE EXPRESIÓN}

En el debate liberal clásico sobre la libertad de expresión, J. S. Mill (1859) abogó por la absoluta libertad de opinión y sentimiento sobre cualquier tema. Sin embargo, introdujo un límite, el "principio de daño". De acuerdo con este principio, un discurso debería limitarse, si supone una violación directa y clara de los derechos fundamentales. Por lo tanto, el valor liberal central -el compromiso de no interferir en la vida de los ciudadanos por parte del Estado o de otras colectividades- a veces se anula (Riley, 2015). De entre todos los tipos posibles de discursos hirientes mencionados por Mill (1859), incluyendo la injuria, la difamación o el insulto, el discurso de odio es la categoría más grave porque puede evolucionar hacia la incitación a la violencia (Bilgrami, 2015).

En el período posterior a la Segunda Guerra Mundial, el Convenio Europeo de Derechos Humanos restringió el uso de la libertad de expresión en el Artículo 10:

Artículo 10 - Libertad de expresión

1. Toda persona tiene derecho a la libertad de expresión. Este derecho comprende la libertad de opinión y la libertad de recibir o de comunicar informaciones o ideas sin que pueda haber injerencia de autoridades públicas y sin consideración de fronteras. El presente artículo no impide que los Estados sometan a las empresas de radiodifusión, de cinematografía o de televisión a un régimen de autorización previa.

2. El ejercicio de estas libertades, que entrañan deberes y responsabilidades, podrá ser sometido a ciertas formalidades, condiciones, restricciones o sanciones, previstas por la ley, que constituyan medidas necesarias, en una sociedad democrática, para la seguridad nacional, la integridad territorial o la seguridad pública, la defensa del orden y la prevención del delito, la protección de la salud o de la moral, la protección de la reputación o de los derechos ajenos, para impedir la divulgación de informaciones confidenciales o para garantizar la autoridad y la imparcialidad del poder judicial. (Consejo de Europa [CoE], 1950).

El Pacto Internacional de Derechos Civiles y Políticos (PIDCP) adoptado por las Naciones Unidas (ONU) en 1966 expresa una posición contra el uso de lenguaje discriminatorio y su expresión radical como "discurso de odio", en su artículo 20:

Cualquier defensa del odio nacional, racial o religioso que constituya incitación a la discriminación, la hostilidad o la violencia estará prohibida por ley (ONU, 1966). 
La descolonización y la globalización han permitido un aumento exponencial en la implementación de este concepto legal. Sin embargo, de manera similar a los esfuerzos para contrarrestar el "discurso de odio", la "libertad de expresión" se conoce en todo el mundo a través del Artículo 19 del PIDCP de la siguiente manera:

Toda persona tendrá derecho a la libertad de expresión; este derecho incluirá la libertad de buscar, recibir e impartir información e ideas de todo tipo, independientemente de las fronteras, ya sea oralmente, por escrito o en forma impresa, en forma de arte o por cualquier otro medio de su elección (ONU, 1966).

Se han empleado diferentes enfoques, que incluyen varios códigos de conducta éticos y medidas legales, tanto nivel nacional como internacional para superar la contradicción entre estos dos artículos del PIDCP. El Código Internacional de Ética Periodística de la UNESCO (1978) presenta 10 principios. El principio 8 de este código promueve el "respeto por los valores universales y la diversidad de culturas". Además, el código aboga por el periodista como agente de la cohesión social, la coexistencia pacífica y de valores democráticos fundamentales tales como la tolerancia y el pluralismo. Sin embargo, este principio es vago y no impide el uso de lenguaje discriminatorio contra grupos vulnerables, como las minorías étnicas, culturales y raciales. Por el contrario, el código de conducta ética del Colegio de Periodistas de Cataluña establece explícitamente los siguientes principios:

- No incluir el grupo étnico, el color de la piel, el país de origen, la religión o la cultura si no es estrictamente necesario para una comprensión global.

- Es necesario evitar generalidades, maniqueísmos y la simplificación de la información. La difusión de noticias a través de clichés deforma la realidad, además de promover una ideología desfavorable sobre las propias minorías étnicas.

- No se debe alentar la información negativa o sensacionalista. Debemos evitar crear conflictos y magnificarlos innecesariamente. Debemos promover la búsqueda de noticias positivas. Llenar los periódicos con noticias negativas sobre las minorías étnicas multiplica el riesgo de caer en el sensacionalismo, y de llevar a la sociedad a tener una imagen distorsionada de las minorías, o incluso a perjudicarlas (Quaderns del CAC, 2002).

El artículo 14 de la Constitución española establece que:

Los españoles son iguales ante la ley, sin discriminación por nacimiento, raza, sexo, religión, opinión o cualquier otra condición o circunstancia personal o social (Congreso de los Diputados, 1978).

Como derecho fundamental, este artículo tiene plena fuerza normativa y afecta a todos los poderes públicos. Sin embargo, este artículo está en conflicto con el 
Artículo 20 que establece otro derecho fundamental: el derecho a la "libertad de expresión":

1. Se reconocen y protegen los derechos:

a) A expresar y difundir libremente los pensamientos, ideas y opiniones mediante la palabra, el escrito o cualquier otro medio de reproducción.

b) A la producción y creación literaria, artística, científica y técnica.

c) A la libertad de cátedra.

d) A comunicar o recibir libremente información veraz por cualquier medio de difusión. La ley regulará el derecho a la cláusula de conciencia y al secreto profesional en el ejercicio de estas libertades.

2. El ejercicio de estos derechos no puede restringirse mediante ningún tipo de censura previa (Congreso de los Diputados, 1978).

El código penal español define varios delitos penales relacionados con el discurso de odio:

Art. 510.1:

1. Serán castigados con una pena de prisión de uno a cuatro años y multa de seis a doce meses:

a) Quienes públicamente fomenten, promuevan o inciten directa o indirectamente al odio, hostilidad, discriminación o violencia contra un grupo, una parte del mismo o contra una persona determinada por razón de su pertenencia a aquél, por motivos racistas, antisemitas u otros referentes a la ideología, religión o creencias, situación familiar, la pertenencia de sus miembros a una etnia, raza o nación, su origen nacional, su sexo, orientación o identidad sexual, por razones de género, enfermedad o discapacidad.

b) Quienes produzcan, elaboren, posean con la finalidad de distribuir, faciliten a terceras personas el acceso, distribuyan, difundan o vendan escritos o cualquier otra clase de material o soportes que por su contenido sean idóneos para fomentar, promover, o incitar directa o indirectamente al odio, hostilidad, discriminación o violencia contra un grupo, una parte del mismo, o contra una persona determinada por razón de su pertenencia a aquél, por motivos racistas, antisemitas u otros referentes a la ideología, religión o creencias, situación familiar, la pertenencia de sus miembros a una etnia, raza o nación, su origen nacional, su sexo, orientación o identidad sexual, por razones de género, enfermedad o discapacidad. (Código Penal, 2015)

El código penal español prohíbe la promoción del odio, la violencia o la discriminación a través de cualquier tipo de discurso. Esta prevención legal se adoptó avant la lettre, respecto de la definición del "discurso de odio" aprobada por la ECRI: 
el discurso de odio se basa en la suposición injustificada de que una persona o un grupo de personas son superiores a los demás; incita a actos de violencia o discriminación, lo que socava el respeto por los grupos minoritarios y daña la cohesión social (ECRI, 2015).

Las medidas contra el discurso el odio han de estar bien fundamentadas y no ser utilizadas de manera arbitraria, de lo contrario se podría incurrir en formas autoritarias de censura. En el periodismo informativo, el discurso de odio ha de suponerse como una línea roja de carácter ético, en primer lugar. Los periodistas y los equipos editoriales deben asumir la responsabilidad de las consecuencias fácticas de las noticias sesgadas, que pueden repercutir en relaciones sociales excluyentes o discriminatorias. Además, el discurso de odio implica un límite legal a la libertad de los medios de comunicación. Pienso, en este sentido, que la regulación de la libertad de expresión debe ser coherente con el artículo 2 del Tratado de la Unión Europea (UE):

La Unión se basa en los valores del respeto a la dignidad humana, la libertad, la democracia, la igualdad, el Estado de derecho y el respeto a los derechos humanos, incluidos los derechos de las personas pertenecientes a minorías. Estos valores son comunes a los Estados miembros en una sociedad con pluralismo, no discriminación, tolerancia, justicia, solidaridad e igualdad (2007).

\section{CONCLUSIONES}

Este artículo examina la correlación entre el antigitanismo estructural y la estigmatización mediática. La construcción del estigma de la "amenaza gitana" se concreta en una representación periodística de la identidad gitana marcada por los signos de la peligrosidad y la criminalidad. Este estigma opera a través de la inducción del miedo social hacia la población gitana.

Estudios recientes han revelado una disparidad entre el alto nivel de "criminalidad percibida" y el bajo nivel de "criminalidad real" en España. En los últimos 10 años, la criminalidad ha sido una de las cinco preocupaciones sociales más prominentes, junto con el desempleo, la corrupción política, la crisis económica y el terrorismo (Caro Cabrera y Navarro Ardoy, 2017; Departamento de Seguridad Nacional [DSN], 2016). Sin embargo, según el Banco Mundial (2016), España es uno de los países con las tasas de homicidios más bajas de la Unión Europea, con Alemania, Francia y Portugal con tasas más altas que España. Con una población de aproximadamente 50 millones, aproximadamente 300 personas son asesinadas cada año en España: es decir, 0,7 de cada 100.000 muertes por año.

Estos datos nos llevan a plantear la siguiente pregunta: ¿qué provoca tal percepción de miedo a los crímenes en España? Desde nuestro estudio de framing analysis podemos responder diciendo que el miedo social no está asociado con las experiencias de crímenes reales, está relacionado con los niveles de exposición virtual a crímenes reportados por los medios. El miedo social no se provoca a través del registro oficial de crímenes reales, sino a través de la frecuencia e intensidad de las historias de crímenes publicadas por los medios de comunicación. 
La construcción del miedo social es aún más falaz y manipuladora, cuando asocia la culpa social del crimen con un grupo étnico-racial en particular. En sus aspectos éticos y legales, la responsabilidad de los crímenes debe atribuirse a las personas que cometen estos crímenes; nunca a agentes abstractos tales como las razas, las culturas o las etnias. Al correlacionar la pertenencia étnico-racial con las marcas antagónicas del bien y del mal, las narrativas informativas contribuyen a reproducir viejos prejuicios y estereotipos, históricamente arraigados, que sirven de base a las divisiones morales y a las jerarquías sociales consolidadas en el tiempo presente.

La relación entre discriminación sistémica y violencia simbólica se puede abordar aquí con tres tesis principales que nos permiten conectar con nuestro framing analysis.

1. Las estructuras simbólicas y epistémicas hegemónicas influyen tanto en el sentido común de la población media como en las ideologías de gobernanza institucionalizadas.

2. Una ideología de gobernanza antigitana, históricamente arraigada durante generaciones, ha colocado a la población gitana en lo más bajo de la estructura de clases. Lo cual se ha traducido en una falta del acceso sistémico a derechos fundamentales.

3. Esta ideología racista no sería moralmente aceptada, en el período democrático actual, sin la inducción mediática del miedo social a la "amenaza gitana".

En el caso del antigitanismo, la construcción simbólica estereotipada genera sentimientos morales de animadversión (derivados del miedo) de la sociedad mayoritaria hacia las personas gitanas. Así, se inhiben las actitudes de empatía, solidaridad o confianza. Estos afectos se originan a partir de determinados patrones narrativos desplegados a través de todo el espectro editorial de los principales medios informativos de España (como ya hemos podido ver).

\section{RECOMENDACIONES}

Para terminar, quiero proponer algunas recomendaciones que podrían emplearse para contrarrestar el racismo (en general) y el antigitanismo (en particular), en el campo del periodismo informativo.

- Los códigos de conducta de los medios informativos deberían prescribir evitar cualquier relación semántica entre la etnicidad y la criminalidad.

- Los Estados deberían introducir legislaciones para garantizar la participación de las minorías étnico-raciales en las actividades de los medios informativos, en varios niveles: la producción de contenido, la toma de decisiones editoriales y las actividades de supervisión. De este modo, los grupos minoritarios podrían contribuir activamente a su representación en los medios de comunicación.

- Los medios informativos deberían producir narrativas que reflejen experiencias de convivencia pacífica entre diferentes culturas o etnias; e historias exitosas de destacados miembros pertenecientes a minorías que hayan contribuido significativamente al progreso de la sociedad. 
- Las autoridades de las diferentes administraciones públicas (ayuntamientos y gobiernos autonómicos y nacionales) deberían organizar formaciones para empresas de noticias, tanto públicas como privadas, para evitar la cobertura estereotipada de las minorías étnico-raciales y para fomentar historias que promuevan la comprensión intercultural / interétnica.

\section{BiBLIOGRAFÍA}

ABC (7 de agosto de 2010) Muere un joven tras un tiroteo a la salida de una discoteca en Torrejón.

Disponible en: http://www.abc.es/20100807/local-madrid/muerto-tiroteo-torrejon201008071250.html (consultado el 10 May 2018).

ABC (22 de mayo 2014) Seis detenidos en Villena por una reyerta con armas de fuego entre familias.

Disponible en: http://www.abc.es/alicante/20140522/abcp-seis-detenidos-villena-reyerta20140522.html

ABC (2 de septiembre de 2015) Una fallecida y cinco hospitalizados en una pelea entre dos clanes de etnia

gitana tras un atropello en Mazarrón.

Disponible en: http://www.abc.es/local-murcia/20150902/abci-pelea-gitanos-mazarron201509022144.html (consultado el 10 May 2018).

Agarin, T (ed.) (2014) When Stereotype Meets Prejudice: Antiziganism in European Societies. Stuttgart: Ibidem Verlag.

Alliance against Antigypsyism (2017) Antigypsyism - A Reference Paper. Brussels.

Bartels, A. et al. (2019) Interlude: Epistemic Violence. In Bartels, A. et al. (eds) Postcolonial Literatures in English. Stuttgart: J. B. Metzler. pp. 153-154.

Bhabha, HK (2011) Our Neighbours, Ourselves: Contemporary Reflections on Survival. Berlin: Hegel Lectures series/De Gruyter.

Bilgrami, A (2015) The Ambitions of Classical Liberalism: Mill on Truth and Liberty. Revue Internationale de Philosophie, 272(2): 175-182.

Bourdieu, P (1979) The Inheritors: French Students and Their Relations to Culture. Chicago: University of Chicago Press.

Caro Cabrera, MJ y Navarro Ardoy, L (2017) La medición del miedo al delito a través de los barómetros del CIS. Reis: Revista Española de Investigaciones Sociológicas (157): 23-44.

Carrera, S, Rostas, I y Vosyliute, L (2017) Combating Institutional Anti-Gypsyism: Responses and Promising Practices in the EU and Selected Member States. Brussels: Centre for European Policy Studies.

Carrera, S, Rostas, I and Vosyliute, L (2018) Study on Scaling up Roma Integration Strategies: Truth, Reconciliation, and Justice for Addressing Antigypsyism. Brussels: European Parliament's Policy Department for Citizens' Rights and Constitutional Affairs.

Carty, LE y Mohanty, CT (eds.) (2018) Feminist Freedom Warriors: Genealogies, Justice, Politics, and Hope. Chicago: Haymarket Books. 
Código Penal (2015) Ley Orgánica 1/2015, de 30 de marzo, por la que se modifica la Ley Orgánica 10/1995, de 23 de noviembre, del Código Penal. Disponible en https://www.boe.es/eli/es/lo/2015/03/30/1/con (consultado 20 junio 2018).

Congreso de los Diputados (1978) Constitución Española. Madrid.

Consejo para la Eliminación de la Discriminación Racial o Étnica (CEDRE) (2014) Percepción de la Discriminación por el Origen Racial o Étnico por parte de las Potenciales Víctimas en 2013. Madrid: Ministerio de Sanidad, Servicios Sociales e lgualdad.

Cortés, I and End, M (eds.) (2019) Dimensions of Contemporary Antigypsyism in Europe. Brussels-Berlin: European Network Against Racism \& Zentralrat Deutscher Sinti und Roma.

Council of Europe (CoE) (1950) Convenio Europeo de Derechos Humanos, firmado en Roma el 4 de noviembre de 1950.

Council of Europe (CoE) (2012) Descriptive glossary of terms relating to Roma issues. Strasbourg, May 18, 2012.

Decade of Roma Inclusion Secretariat Foundation (DRISF) (2013). Civil Society Monitoring Report on the Implementation of the National Roma Integration Strategy and Decade Action Plan in 2012 in Spain. Report. Budapest, Hungary: Decade of Roma Inclusion Secretariat Foundation.

De la Rica, S (2019) Estudio Comparado sobre la Situación de la Población Gitana en España en Relación al Empleo y la Pobreza 2018. Madrid: Fundación Secretariado Gitano/Fundación ISEAK.

De los Santos, T. M., and Nabi, R. L. (2019). Emotionally Charged: Exploring the Role of Emotion in Online News Information Seeking and Processing. Journal of Broadcasting \& Electronic Media, 63(1): 39-58.

Departamento de Seguridad Nacional (DSN) (2016). Estadísticas de Criminalidad en España, 2016. Gabinete de la Presidencia. Gobierno de España.

El Mundo (21 de mayo de 2014) Seis detenidos por su implicación en una reyerta con armas de fuego. Disponible en:

http://www.elmundo.es/comunidadvalenciana/2014/05/21/537cc05622601dbc1 a8b4573. html (consultado el 20 de mayo de 2018).

El Mundo (2 de septiembre de 2015) Un muerto y cinco heridos en una pelea entre dos clanes de etnia gitana tras un atropello en Mazarrón. Disponible en: http://www.elmundo.es/espana/2015/09/02/55e7433c46163fad7b8b4584.html (consultado el 20 May 2018).

El País (8 de agosto de 2010) Muere un hombre de un balazo frente a una discoteca de Torrejón.

Disponible en: https://elpais.com/diario/2010/08/08/madrid/1281266658_850215.html (consultado el 18 de mayo de 2018).

El País (21 de mayo de 2014) Seis detenidos por una reyerta con armas de fuego en Villena. https://elpais.com/ccaa/2014/05/21/valencia/1400687033_589259.html (consultado el 18 May 2018).

End, M (2019) Subtle Images of Antigypsyism. An Analysis of the Visual Perception of 'Roma'. En: Cortés I and End M (eds.) Dimensions of Contemporary Antigypsyism in Europe. Brussels-Berlin: European Network Against Racism \& Zentralrat Deutscher Sinti und Roma. pp. 67-88. 
End, M y Selling, J (eds.) (2015) Antiziganism: What's in a Word? Cambridge: Cambridge Scholars Publishing.

European Anti-Poverty Network (2019) El estado de la pobreza. Seguimiento del indicador de pobreza y exclusión social en España 2008-2018. Madrid. Octubre.

Eurobarometer (2012). Immigrants and Out-Groups in Western Europe. Report no. 2012239, Köln, Germany: GESIS Leibniz Institute for the Social Sciences.

Eurobarómetro sobre discriminación en la UE, 2019. Disponible en : https://ec.europa.eu/commfrontoffice/publicopinion/index.cfm/Survey/getSurvey Detail/instruments/SPECIAL/surveyKy/2251

European Commission (2012) Communication from the Commission to the European Parliament, the Council, the European Economic and Social Committee and the Committee of the Regions. National Roma Integration Strategies: a first step in the implementation of the European Union Framework. Brussels, 21.5.2012. COM (2012) 226 final.

European Commission against Racism and Intolerance (ECRI) (2011) General Policy Recommendation No. 13 on combating anti-gypsyism and discrimination and Roma, aprobada en Estrasburgo el 24 de junio de 2011.

European Commission against Racism and Intolerance (ECRI) (2015) General Policy Recommendation n.15 on Combating Hate Speech. Strasbourg, December 8, 2015.

European Parliament (2015) European Parliament Resolution of 15 April 2015 on the Occasion of International Roma Day Anti-Gypsyism in Europe and EU Recognition of the Memorial Day of the Roma Genocide During World War II.

European Parliament (2017) European Parliament Resolution of 25 October 2017 on Fundamental Rights Aspects in Roma Integration in the European Union: Fighting Anti-Gypsyism.

European Union (2000) Race Equality Directive, Council Directive 2000/43/EC of 29 June 2000 implementing the principle of equal treatment between persons irrespective of racial or ethnic origin.

European Union (2007) Treaty of Lisbon amending the Treaty on European Union and the Treaty establishing the European Community, signed at Portugal on 13 December 2007.

European Union Fundamental Rights Agency (FRA) (2016) EU MIDIS II "Second European Union Minorities and Discrimination Survey Roma - Selected findings".

European Union Agency for Fundamental Rights Agency (FRA) (2018) A Persisting Concern: Anti-Gypsyism as a Barrier to Roma Inclusion.

Galván-Álvarez, E (2010) Epistemic violence and retaliation: the issue of knowledges in Mother India. Atlantis, 32(2): 11-26.

Hancock, I (2002) We are the Romani people, Ame sam e Rromane dzene. Hatfield: Centre de recherches tsiganes/University of Hertfordshire Press.

Hernández, M. (coord.) (2013) Vivienda y exclusión residencial. Murcia: Editum.

Hurley, R. J., Jensen, J. (Jake), Weaver, A., and Dixon, T. (2015). Viewer Ethnicity Matters: Black Crime in TV News and Its Impact on Decisions Regarding Public Policy. Journal of Social Issues, 71(1): 155-170. 
Jakobsson, $\mathrm{P}$ y Stiernstedt, $\mathrm{F}$ (2018) Voice, silence and social class on television. European Journal of Communication, 33(5): 522-539.

Kelsey, D (2017) Media and Affective Mythologies: Discourse, Archetypes and Ideology in Contemporary Politics. London: Palgrave Macmillan.

Kóczé, A y Rövid, M (2019) The Europeanisation of Racial Neoliberalism: The Case of "Roma" and "Refugees". En: Cortés I and End M (eds.) Dimensions of Contemporary Antigypsyism in Europe. Brussels-Berlin: European Network Against Racism \& Zentralrat Deutscher Sinti und Roma. pp. 107-123.

Kostka, J. (2019) Financing Roma Inclusion with European Structural Funds: Why Good Intentions Fail. New York. Routledge.

Kovats, M y Law, I (2018) Rethinking Roma. Identities: Politicisation and New Agendas. London: Palgrave Macmillan.

Kuypers, JA (2006) Bush's War: Media Bias and Justifications for War in a Terrorist Age. Washington, DC: Rowman \& Littlefield Publishers.

La Parra-Casado, D y Jiménez González, N (2016) Sastipen aj Rroma: Desigualdad en salud y comunidad gitana. Alicante: Universidad de Alicante.

Laparra, M et al. (2011) Diagnóstico social de la comunidad gitana en España. Un análisis contrastado de la Encuesta del CIS a Hogares de Población Gitana 2007. Madrid: Ministerio de Sanidad, Política Social e Igualdad.

La Razón (7 de agosto de 2010) Venganza en la «Pícaro». Disponible en: https://www.larazon.es/historico/7224-dos-heridos-uno-muy-grave-al-sertiroteados-en-la-puerta-de-una-discoteca-OLLA_RAZON_299262 (Consultado el 20 de mayo de 2018).

Matache, A y Oprea, A. (2019) Reclaiming the narrative: A critical assessment of terminology in the fight for Roma Rights. En: Cortés I and End M (eds.) Dimensions of Contemporary Antigypsyism in Europe. Brussels-Berlin: European Network Against Racism \& Zentralrat Deutscher Sinti und Roma. pp. 276-300.

Mbembe, A (2017) Critique of Black Reason. Durham: Duke University Press.

Medina, J (2019) Racial violence, emotional friction, and epistemic activism. Angelaki: Journal of Theoretical Humanities, 24(4): 22-37.

Mill, JS (1859). On Liberty. London: John W. Parker \& Son.

Ministerio de Sanidad, Servicios Sociales e Igualdad (2016). Estudio-Mapa sobre Vivienda y Población Gitana, 2015. Madrid.

Petrova, Dimitrina (2003) The Roma: Between a Myth and the Future. Social Research, 70: 111-161.

Picker, G (2017) Racial Cities. Governance and the Segregation of Romani People in Urban Europe. London: Routledge.

Quaderns del CAC (2002) Manual d'estil sobre minories etniques del collegi de periodistes de Catalunya. Tema monogràfic: Mitjans de Comunicació i Immigració, pp. 68-70.

Real Academia Española (2018) Diccionario de la lengua Española. Disponible en: https://dle.rae.es (consultado el 5 de mayo de 2019).

Riley, J (2015) The Routledge Philosophy Guidebook to Mill's on Liberty. New York: Routledge.

Rostas, I (2019) A Task for Sisyphus: Why Europe's Roma Policies Fail. Budapest: Central European University. 
Ryder, AR y Taba, M (2018) Roma and a Social Europe: the role of redistribution, intervention and emancipatory politics. Journal of Poverty and Social Justice, 26(1): 59-75.

Sigona, N. and Vermeersch, P. (2012). The Roma in the new EU: Policies, frames and everyday experiences. Journal of Ethic and Migration Studies, 38(8): 189-1193.

Sneath, D (2016) Tribe. In Stein F. et al. (eds) The Cambridge Encyclopedia of Anthropology. Disponible online http://www.anthroencyclopedia.com/entry/tribe (acceso 30 de junio de 2018).

Spivak, GC (1994) Can the subaltern speak? En: Williams P and Chrisman L (eds.) Colonial Discourse and Post-colonial Theory. New York: Columbia University Press. pp. 66-111.

Spivak, GC and Guha, R (1988) Selected Subaltern Studies. Oxford: Oxford University Press.

United Nations Education, Science, and Cultural Organization (UNESCO) (1978) Declaration on Fundamental Principles concerning the Contribution of the Mass Media to Strengthening Peace and International Understanding, to the Promotion of Human Rights and to Countering Racialism, Apartheid and Incitement to War. Paris: UNESCO.

United Nations (UN) (1965) International Convention on the Elimination of All Forms of Racial Discrimination. Aprobada por la Asamblea Nacional de Naciones Unidas. Resolución 2106 (XX).

United Nations (UN) (1966) International Covenant on Civil and Political Rights (ICCPR). Aprobada por la Asamblea Nacional de Naciones Unidas el 16 de diciembre de 1966. Resolución 2200A (XXI).

United Nations (UN) (2018) Promoting Inclusion through Social Protection. Report on the World Social Situation. New York: United Nations.

World Bank (WB) (2016). Intentional homicides (per 100,000 people): Global Trends 2010/16. Report, Washington DC: The World Bank. 